Rutten, E. A., Deković, M, Stams, G. J. J. M., Schuengel C., Hoeksma, J. B., \& Biesta G. J. J. (2008).

On-and off-field antisocial and prosocial behavior in adolescent soccer players: A multilevel study

J ournal of Adolescence, 31 (3), 371-387

URL: http://dx.doi.org/10.1016/j.adolescence.2007.06.007 


\title{
On-and off-field antisocial and prosocial behavior in adolescent soccer players: A multilevel study
}

Esther A. Rutten, Maja Deković, Geert Jan J.M. Stams, Carlo Schuengel, Jan B. Hoeksma, Gert J.J. Biesta

\begin{abstract}
This study investigated to what extent team membership predicts on-and offfield antisocial and prosocial behavior in (pre)adolescent athletes. Effects of team-membership were related to characteristics of the team environment, such as relational support from the coach towards team members, fair play attitude and sociomoral reasoning within the team, and sociomoral climate. The sample consisted of $\mathrm{N}=331$ male soccer players. Multilevel analyses revealed that $21 \%$ of the variance in off-field antisocial behavior, and $8 \%$ and $14 \%$ of the variance in on-field antisocial and prosocial behavior, respectively, could be attributed to characteristics of the sporting environment, including relational support from the coach, exposure to high levels of sociomoral reasoning about sports dilemmas, and positive team attitude toward fair play. The results highlight the importance of contextual factors in explaining both antisocial and prosocial behavior in adolescent athletes and emphasize the role of organized youth sports as a socialization context.
\end{abstract}

Compared to family and school, the context of organized leisure activities has received scant attention with respect to its socializing potential and its influences on adolescent development (e.g., Duncan, Duncan, Strycker, \& Chaumeton, 2002; McHale, Crouter, \& Tucker, 2001). Yet, sports represent one of the most important organized leisure activities for school-aged children and adolescents. No less than $68 \%$ of Dutch (pre)adolescents participate in organized youth sports (CBS, 1999), a percentage that is comparable to percentages of youth sports participation in North America (NCYS, 2001). Participation in organized youth sports yields specific experiences for children and provides them with new opportunities. Young athletes not only get opportunities to acquire the specific skills and knowledge they need to perform their sports; they are also exposed to the moral values that are the foundation of sports-related rules and norms (Simon, 2000). 
Studies examining the degree to which sport exerts an influence on (pre)adolescent development have largely focused on athletes' antisocial behavior (e.g., norm trespassing and externalizing behavior, such as aggression) and prosocial behavior (e.g., helping, sharing, and supporting others). These studies, however, have yielded mixed results. For example, Bartko and Eccles (2003) reported that adolescents highly involved in sports were rated low on externalizing behavior by their parents. Similarly, sport was associated with less antisocial behavior in a study conducted by McMahon (1990). On the other hand, Endresen and Olweus (2005) reported negative effects resulting from participating in power sports. In their longitudinal study, they found an increase of antisocial involvement outside the sports situation, which they attributed to both practicing power sports itself and repeated contact with 'macho' attitudes, norms, and ideals. Negative outcomes were also found in studies conducted by Barber, Eccles, and Stone (2001), Begg, Langley, Moffitt, and Marshall (1996) and Mutrie and Parfitt (1998). Rees, Howell, and Miracle (1990) found mixed results in their study of high school sports. They reported small positive effects not only on prosocial but also on antisocial behavior (e.g., aggression).

Most studies have focused on athletes' antisocial and prosocial behavior either within the sports context or in general. Our previous study of adolescent sports participation focused on antisocial and prosocial behavior in general (Rutten et al., 2007). In order to reach a better understanding of organized youth sports' possible influences on antisocial and prosocial behavior, a distinction between on-and off-field behaviors in athletes within the sports context should be made. The aim of the present study is to examine factors contributing to adolescent athletes' antisocial and prosocial behavior, both on-field (during the match or training, when there are sportsrelated rules and supervision from the coach and eventually the referee) and off-field (before or after the match or training, when there are no sportsrelated rules and less supervision from the coach and the referee).

The study focuses on youth soccer as it is the sport with the highest participation rate among adolescents in Europe. But there is an additional reason to focus on soccer. It is a contact sport that is performed between teams, which means that on the one hand there is a greater risk for on-field instrumental and hostile aggression, whereas on the other hand sportsrelated rules exist to prevent on-field antisocial behavior. Many other sports, especially individual non-contact sports, would not elicit on-field hostile aggression or other antisocial behaviors. In these sports there is little need for rules and referees regulating antisocial behavior.

As soccer is a team sport, soccer players are exposed to team influences, while all team members share the same socializing factors, such as relational support provided by the coach, athletes' and coaches' attitudes toward fair 
play, athletes' sociomoral reasoning about sports dilemmas, and sociomoral team atmosphere. Accordingly, not only personal characteristics and experiences should be studied as factors influencing athletes' behaviors, but also contextual or team characteristics. In the present study, multilevel analysis is used in order to study the unique contribution of individual and team level characteristics to antisocial and prosocial behavior in (pre)adolescent soccer players. Effects at the team level should receive special attention, because interventions are most easily carried out at that level.

An important feature of organized youth sports is the presence of nonparental adults or natural mentors who may provide relational support, guidance, encouragement, advice, and serve as positive role models (Beam, Chen, \& Greenberger, 2002; Rhodes, Bogatt, Roffman, Edelman, \& Galasso, 2002). Natural mentoring relationships have been studied from several theoretical orientations, including social learning theory, which emphasizes that human behavior is learned through modeling, that is, from observing the behaviors, emotional reactions, and attitudes of other people (Bandura, 1977). According to social learning theory, supportive coaches are expected to serve as a positive role model for the interaction with peers, and are likely to teach their athletes social skills that may generalize to other relationships. Moreover, they may foster behavioral adjustment through offering athletes the opportunity to experience the effects of their own behavior, by providing contingent support, structuring learning activities and joint problem solving.

Empirical support for the positive influence of natural mentoring on adolescent behavioral adjustment was found in several studies (Parra, DuBois, Neville, \& Pugh-Lilly, 2002; Scholte, Van Lieshout, \& Van Aken, 2001; Zimmerman, Bingenheimer, \& Notaro, 2002). Research in the context of organized youth sports revealed that supportive coach-athlete relationships were associated with less antisocial behavior in adolescent athletes (Rutten et al., 2007). Some studies point at negative outcomes when adolescents are confronted with ineffective mentors (e.g., Grossman \& Rhodes, 2002; Slicker \& Palmer, 1993). A qualitative study among young competitive swimmers and soccer players (Biesta et al., 2001) showed that supportive coach-athlete relationships may foster positive (pre)adolescent behavioral adjustment in terms of less antisocial and more prosocial behavior, whereas coaches who are hostile, rejecting, and unresponsive may even harm (pre)adolescent athletes' behavioral adjustment, especially in a performance-oriented motivational atmosphere, where winning or losing a game is regarded to be more important than demonstrating mastery.

In addition, it appears that coaches' attitudes toward fair play may influence their athletes' antisocial and prosocial behavior (Biesta et al., 2001). This is in line with results from a study among soccer players, showing that norms 
held by the coach regarding fair play and aggression were decisive for the players' moral choices when confronted with moral sports dilemmas (Guivernau \& Duda, 2002). Other studies, too, showed that the fair play attitude of the coach influences the extent to which athletes display or have a disposition to show on-field antisocial behavior, including aggression, cheating, and willingness to injure (Luxbacher, 1986; Shields, Bredemeier, Gardner, \& Bostrom, 1995; Stephens, 2001).

The fair play attitude of athletes has most frequently been the target for interventions to enhance the socializing impact of sports (Junge et al., 2000). Although unfair game tactics are penalized in sports, many transgressions go unnoticed and may be rewarded irregularly, which could produce antisocial behavior by means of intermittent reinforcement. Fairness, on the other hand, will only be reinforced if it is followed by social rewards. Research among soccer players showed that the use of fair game tactics was predicted especially by team values concerning fair play (Aziz, 1998; Stephens \& Bredemeier, 1996). It is therefore imperative that fair play attitude be studied not only at the individual level but also at the team level.

A more general process guiding on-and off-field behavior is moral reasoning about sports-related dilemmas. Shields and Bredemeier (1995) reported that boys were reasoning at lower moral levels-that is more egocentric and instrumental and less empathic and prosocial-when responding to sportsspecific dilemmas instead of general daily dilemmas (Bredemeier \& Shields, 1986a, 1986b). Stevenson (1998) found that student athletes reasoned at lower moral levels than students who did not participate in sports when issues of social responsibility were discussed. Rutten et al. (2007) showed that higher levels of moral reasoning about sports dilemmas were associated with more prosocial behavior in adolescent athletes.

A positive sociomoral climate, as defined by the degree to which norms are created, shared, and justified through dialogue and have become part of the athlete's self-articulation (Higgins-D'Alessandro \& Sadh, 1998; Power, Higgins, \& Kohlberg, 1989), appears to be important not just because it can stimulate moral awareness (cf. Boom, 1991), but also because antisocial and prosocial behavior have been shown to be determined to an important extent by the sociomoral climate of the environment both in schools (Brugman et al., 2003; Higgins, Power, \& Kohlberg, 1984; Høst, Brugman, Tavecchio, \& Beem, 1998; Power et al., 1989) and in the context of organized youth sports (e.g., Guivernau \& Duda, 2002; Rutten et al., 2007; Stephens, 2000). Ommundsen, Roberts, Lemyre, and Treasure (2003) showed that a positive mastery-oriented sports climate proved to be associated with higher levels of sociomoral reasoning and a reduction of antisocial behavior in adolescent male soccer players. 
In sum, most studies of extracurricular or leisure activities have focused on the time youths spend in various activities in relation to behavioral outcomes. Only few studies have examined variations across activity contexts or have used indicators beyond participation to predict behavioral outcomes. More comprehensive research in the sports context provided evidence that a supportive coach-athlete relationship, fair play attitude of coaches and athletes, sociomoral reasoning, and sociomoral team climate affect antisocial and prosocial behavior in adolescent athletes. However, as a rule, only the effects of a single factor have been studied, leaving open the possibility that the effects of these factors might not be independent.

The present study investigates on-and off-field antisocial and prosocial behavior in (pre)adolescent soccer players. Antisocial behavior is expected to be negatively associated with the quality of the relationship with the coach, coaches' and athletes' fair play attitude, moral reasoning about sports-related dilemmas, and the sociomoral climate, whereas prosocial behavior is expected to be positively associated with these factors. For both on-field and off-field behavior the same associations are hypothesized. A multilevel design is used to separately assess effects at the individual and team level. Effects at the team level can be difficult to interpret if team members not only share the team environment, but also a similar background that is associated with outcomes. Cultural background and socioeconomic status were therefore included as control variables. Because in youth sports, teams are composed of same-aged children, age was also added as a control variable. Sportsrelated coach characteristics (formal education in sports and years of coaching in general and at the present club) were included, as these factors may account for differences in coach-athlete relationship quality as well as athlete conduct. Because the study relied on questionnaire self-report, the athletes' tendency to give socially desirable answers and their verbal intelligence were also assessed. It is a repeated finding that verbal intelligence is more strongly associated with antisocial behavior than is nonverbal intelligence (Jensen, 1998). Notably, studying aggressive behavior in boys from age 6-15 years, Nagin and Tremblay (2001) found low verbal IQ to be associated with a nearly two fold increase in the odds of a high aggression trajectory.

\section{Method}

\section{Participants}

In total, $N=11$ soccer clubs, including 43 teams, participated. These clubs were randomly drawn from all soccer clubs in the four largest cities in the Netherlands. In total, 331 boys, aged 9-19 years, completed questionnaires. Each soccer team was represented by $3-13$ athletes $(M=7.7 ; S D=2.9)$ and one or two coaches. The average age of the athletes was 14.0 years (SD = 
2.0). Their socioeconomic status was determined by combining the educational and occupational background of both parents (Van Westerlaak, Kropman, \& Collaris, 1990) and was computed on the basis of samplespecific factor loadings and standard deviations. Mean scores correspond to socioeconomic strata in the following way: 3-9, lower class; 9-12, middle class; and 12-16, upper class (Bernstein \& Brandis, 1970). The internal consistency reliability of the scale for socioeconomic status was sufficient, $\alpha=$ .79 (four items). The mean score was 6.6 (SD = 2.2), which indicated that the sample could be considered as lower class.

The percentages of athletes with a Caucasian white (indigenous) and ethnic minority (nonindigenous) background were almost equal, that is, $51 \%$ and $49 \%$, respectively. Athletes were considered to have an ethnic minority background if at least one of their parents had been born in a country that is or was part of the ethnic minority or integration policy of the Dutch government. On average, the athletes had been active in sports for 7 years, and they visited their soccer club approximately 3 days a week. Of the athletes $19 \%$ were active in sports less than $5 \mathrm{~h}$ a week, 38\% between 5 and $10 \mathrm{~h}$ a week, and $43 \%$ more than $10 \mathrm{~h}$ a week. On average, they had known their coach for 3 years and they were currently seeing him $5 \mathrm{~h}$ a week.

In total $\mathrm{N}=54$ coaches participated in the present study. If teams had two coaches, we included both coaches and calculated their mean score. The average age of the coaches was 41 years. The socioeconomic background of the coaches was middle class: $M=9.8(S D=3.7)$. On average, they had 8 years coaching experience, of which 5 years at the current soccer club: $51 \%$ of the coaches had attended formal coach education courses. All coaches were male. Only four coaches had a cultural minority background.

\section{Measures}

Verbal intelligence: The subtask Analogical Reasoning of the Groninger Intelligence Test (Luteijn \& Van der Ploeg, 1983; Zwanepol, Berghuis, De Groot, \& Luteijn, 2002) was used to estimate the level of the athletes' verbal intelligence. This subtask consists of 20 multiple-choice items, in which the respondent is asked to make a logical connection between words. Two word combinations are given, the respondent is asked to fill in the third word (e.g., "furnisher-work-shop", "accountant-office", "gardener-?", with the answer options: "grapes", "lettuce", "clay", "greenhouse" and "spring"). The internal consistency reliability was $\alpha=.71$ (14 items).

Social desirability. The social desirability scale (15 items) measures the tendency to give socially desirable answers and is based upon the MarloweCrowne Social Desirability Scale (Crowne \& Marlowe, 1960). Examples of 
items are: "I am always honest", and "I never boast". Respondents indicate whether statements apply to them by using the answer categories "true", and "false". The internal consistency reliability was $\alpha=.82$ (15 items).

Sociomoral reasoning about sports dilemmas. The Practical Sociomoral Reflection Objective Measure-Sport (PSROM-Sport) was developed to assess practical sociomoral reasoning in the context of organized youth sports by Rutten et al. (2007). It is an adaptation of the Sociomoral Reflection Objective Measure-Short Form, the SROM-SF (Basinger \& Gibbs, 1987; Høst et al., 1998). The PSROM-Sport is a multiple choice questionnaire containing moral dilemmas in the context of organized youth sports (e.g., "You decide to help the best player in the team to get fit after an injury, so that he might be ready in time for the most important match of the year"). Each question is followed by nine question arrays tapping the type of sociomoral norms the person uses, for example, "Without this player you might lose the important match" (Kohlberg's stage 1: unilateral reasoning), "Because this player might help you too" (stage 2: instrumental reasoning), "If you do not, you are not acting as a real friend" (stage 3: mutualprosocial reasoning), "It shows that you feel responsible for your team" (stage 4: systemic reasoning). The internal consistency reliability of the PSROM-Sport was sufficient, that is, $\alpha=.63$ (nine items).

Rutten et al. (2007) found evidence for convergent validity by comparing moral scores on the PSROM-Sport with scores on semi-structured interviews assessing sociomoral reasoning competence (Gibbs, Basinger, \& Fuller, 1992) and fair play attitude (Junge et al., 2000; Loland \& McNamee, 2000; Tamboer \& Steenbergen, 2000). The PSROM-Sport proved to be significantly and moderately associated with both sociomoral reasoning competence and fair play attitude in the expected direction. In the present study discriminant validity was established by computing correlations between sociomoral reasoning in the context of organized youth sports and both social desirability and verbal intelligence. No significant correlations were found, which supports discriminant validity of the PSROM-Sport.

Attitude toward fair play (athlete and coach): The Fair Play Questionnaire assesses the extent to which athletes and coaches have respect for the opponent and the formal and informal rules of the game (Junge et al., 2000; Loland \& McNamee, 2000; Tamboer \& Steenbergen, 2000). The fair play attitude of the athlete was assessed by means of self-report (11 items, e.g., "Winning is more important than respect for the rules of the game"). The response categories (5-point Likert-type scale) varied from "totally disagree" to "totally agree". The fair play attitude of the coach was assessed by means of athlete report (12 items, e.g., "For my coach, hidden fouls are part of the game"). The internal consistency for fair play attitude of athletes and coaches was .76, and .78, respectively. No significant correlations were found between attitude toward fair play and social desirability and verbal 
intelligence.

Relational support: Relational support provided by the coach was measured using the Relational Support Inventory (RSI) from Scholte et al. (2001). This questionnaire measures relational support in terms of acceptance, emotional support, respect for autonomy, quality of communication, and convergence of goals. Athletes responded to 23 items (e.g., "My coach lets me solve my problems as much as possible, but he helps me out when I ask him to"), on a 5-point scale ranging from "totally disagree" to "totally agree". The alpha was .89. Relational support was not significantly associated with social desirability, and the association with verbal intelligence was significant, but modest, with $r=.34, p<.001$.

Sociomoral team atmosphere. Sociomoral team atmosphere in terms of normative expectations, manners, communication, and possibilities for participation was measured by an adapted version of the School Culture Scale (SCS) (Higgins, 1995; Higgins-D'Alessandro \& Sadh, 1998; Veugelers \& De Kat, 1998), an instrument assessing culture as a system of integrated norms, which was derived from qualitative moral atmosphere interviews conducted during a study of Just Community programs in the United States (Power et al., 1989). The SCS was adapted by Rutten et al. (2007) for use in organized youth sports by making the items sports-specific and removing items that had no meaning in the context of organized youth sports. Athletes indicated on a 5-point scale the degree to which statements about the sociomoral atmosphere of their sporting environment were true or untrue (e.g., "In this team, you can rely on each other"). The internal consistency reliability was $\alpha=.84$ (15 items). Sociomoral team atmosphere correlated significantly and weakly with social desirability, $r=.26, p<.001$, but it was not significantly associated with verbal intelligence.

On-and off-field antisocial and prosocial behavior: The dependent variables on-and off-field antisocial and prosocial behavior were assessed with the Sports Behavior Inventory (SBI), which was based upon the Anti Social Behavior Inventory (ASBI) from Wouters and Spiering (1990) and the Prosocial Behavior Questionnaire (PBQ) from Weir and Duveen (1981), respectively. Athletes indicated on 4-point Likert-type scales the degree to which they behave in a certain way (varying from "never" to "always"). An example of an item representing on-field antisocial behavior is: "I shout abuse to others during matches". An example of an item representing offfield prosocial behavior is: "If there's an argument in the changing room, I try to do something about it".

A principal components analysis revealed a 4-factor-solution, accounting for $47 \%$ of the variance, which indicated that on-and off-field antisocial and prosocial behavior could be considered as separate dimensions. The 
moderate amount of variance explained in the factor analysis indicates that on-and off-field antisocial and prosocial behaviors were measured with a certain amount of error. However, each scale showed satisfactory reliability. We found internal consistency reliabilities of $a=.80$ for on-field antisocial behavior (eight items), $a=.66$ for on-field prosocial behavior (five items), $a=$ .90 for off-field antisocial behavior (10 items), and $a=.76$ for off-field prosocial behavior (nine items). Only off-field prosocial behavior correlated significantly with social desirability, but the relation was weak, $r=.25, p<$ .001 . We found no significant associations between athletes' behavior and social desirability. Only off-field antisocial behavior was significantly and moderately associated with verbal intelligence, $r=.38, p<.001$.

\section{Results}

\section{Multilevel analyses}

Multilevel analysis (Goldstein, 1995) was used in order to examine the contribution of educationally relevant factors in organized youth sports to onand off-field antisocial and prosocial behavior among pre(adolescent) athletes. Table 1 shows simple correlations between independent general and sports-specific background variables of the athletes (age, socioeconomic status, cultural background, and years and extent of sports participation), background variables of the coach (formal education in sports, years active as a coach in general and at the present club), control variables (social desirability and verbal intelligence), explanatory factors (sociomoral atmosphere, fair play attitude of the athlete and coach, sociomoral reasoning, and relational support), and dependent variables (on-and off-field antisocial and prosocial behavior). The associations between the independent variables were generally low to moderate. We found significant associations in the expected direction between explanatory variables-including fair play attitude, sociomoral reasoning, sociomoral atmosphere, and relational support provided by the coach-and on-and off-field antisocial and prosocial behavior.

The explanatory variables can be considered both as characteristics of individual soccer players (individual level) and as team characteristics (contextual level). Group-mean centering (Snijders \& Bosker, 1999) was used to split explanatory variables into one variable at the team level and one at the individual level, calculating the mean score of the team (contextual level), and subsequently subtracting the mean score from the individual athletes' scores (individual level). Whereas the contextual level reflects commonalities between team members (e.g., shared perception of the sociomoral team atmosphere), the individual level reflects differences between athletes within teams (e.g., the extent to which the individual 
perception of the sociomoral team atmosphere deviates from the team average).

A hierarchical procedure was followed in analyzing the data. Firstly, we examined whether significant contextual effects could be distinguished (i.e., significant between team differences in on-and off-field antisocial and prosocial behavior) in the model without explanatory factors (the so-called null-model). Then, in six consecutive steps, the explanatory factors were entered blockwise, testing whether the contextual explanatory model (steps five and six) would be a significant improvement over the individual explanatory model (steps one-four). Whenever an inserted block did not result in a significant improvement of the model, the variables were removed. Thus, only the variables with statistically significant effects are represented in the final model.

In the first step, we controlled for the athlete's general background variables (age, socioeconomic status, and cultural background). In the second step, the athletes' sports-specific background variables were controlled for (years and extent of sports participation). In the third step, we added the athlete's social desirability and verbal intelligence. In the fourth step, the athlete's individual level explanatory factors were entered in the model, indicating within team differences between individual team members (perceived sociomoral team atmosphere, fair play attitude of the athlete and perceived fair play attitude of the coach, individual sociomoral reasoning, and perceived relational support from the coach). In the fifth step we controlled for coach background variables (formal education in sports, years active as a coach in general and at the present club). Finally, in the sixth and final step we added explanatory variables at the contextual level (shared perception of the sociomoral team atmosphere, fair play attitude of the team and the coach, the team's level of sociomoral reasoning, and the team's experienced relational support). 
Table 1

Means, standard deviations, and correlations between background variables of athletes and coaches, social desirability, verbal intelligence, explanatory variables, and the dependent variables on- and off-field antisocial and prosocial behavior

\begin{tabular}{|c|c|c|c|c|c|c|c|c|c|c|c|c|c|c|c|c|c|c|c|c|c|}
\hline Variables & $M$ & $S D$ & 1 & 2 & 3 & 4 & 5 & 6 & 7 & 8 & 9 & 10 & 11 & 12 & 13 & 14 & 15 & 16 & 17 & 18 & 19 \\
\hline \multicolumn{22}{|l|}{ Control variables } \\
\hline 1. Age & 14.01 & 1.96 & 1.00 & & & & & & & & & & & & & & & & & & \\
\hline 2. Socioeconomic status & 6.66 & 2.25 & .11 & 1.00 & & & & & & & & & & & & & & & & & \\
\hline 3. Cultural background ${ }^{\mathrm{a}}$ & 1.51 & .50 & -.16 & -.03 & 1.00 & & & & & & & & & & & & & & & & \\
\hline 4. Extent of participation & 10.89 & 7.20 & .01 & .03 & .08 & 1.00 & & & & & & & & & & & & & & & \\
\hline 5. Years of participation & 7.22 & 2.97 & $.57^{*}$ & .12 & $-.31^{*}$ & .00 & 1.00 & & & & & & & & & & & & & & \\
\hline 6. Years coach in general & 7.69 & 5.48 & .01 & .13 & -.08 & -.11 & .07 & 1.00 & & & & & & & & & & & & & \\
\hline 7. Years coach at club & 5.22 & 3.96 & $-.24^{*}$ & .00 & -.08 & -.11 & -.08 & $.60^{*}$ & 1.00 & & & & & & & & & & & & \\
\hline 8. Formal education in sports (coach) & 1.36 & .48 & $.39 *$ & .07 & $-.29^{*}$ & -.03 & $.27^{*}$ & .18 & $-.22 *$ & 1.00 & & & & & & & & & & & \\
\hline 9. Social desirability & 1.47 & .25 & -.06 & -.00 & .08 & .02 & -.07 & .03 & .00 & -.06 & 1.00 & & & & & & & & & & \\
\hline 10. Verbal intelligence & 7.86 & 2.89 & .18 & .01 & $-.20^{*}$ & -.12 & .17 & .03 & .14 & .06 & -.15 & 1.00 & & & & & & & & & \\
\hline \multicolumn{22}{|l|}{ Explanatory variables } \\
\hline 11. Moral reasoning about sports dilemmas & 2.83 & .40 & .01 & .02 & -.07 & -.01 & .08 & -.06 & .04 & -.00 & -.04 & .18 & 1.00 & & & & & & & & \\
\hline 12. Fair play attitude athlete & 3.45 & .67 & $-.25^{*}$ & -.04 & .05 & -.02 & -.15 & -.09 & .17 & $-.25^{*}$ & .13 & .07 & $.28^{*}$ & 1.00 & & & & & & & \\
\hline 13. Fair play attitude coach & 3.63 & .59 & -.12 & .05 & -.05 & -.06 & -.02 & .04 & .15 & -.12 & .09 & .18 & $.25^{*}$ & $.45^{*}$ & 1.00 & & & & & & \\
\hline 14. Relational support by the coach & 3.73 & .62 & .02 & .05 & $-.21^{*}$ & -.10 & .08 & .04 & .10 & .07 & -.03 & $.34^{*}$ & $.40^{*}$ & $.26^{*}$ & $.48^{*}$ & 1.00 & & & & & \\
\hline 15. Sociomoral team atmosphere & 3.56 & .70 & $-.29^{*}$ & -.06 & .06 & -.02 & -.17 & -.02 & $.20^{*}$ & $-.26^{*}$ & $.26^{*}$ & .02 & .11 & $.36^{*}$ & $.35^{*}$ & $.26^{*}$ & 1.00 & & & & \\
\hline \multicolumn{22}{|l|}{ Dependent variables } \\
\hline 16. On-field antisocial behavior & 2.05 & .61 & .13 & .00 & .05 & .01 & .06 & .02 & -.16 & .09 & -.07 & -.16 & $-.24^{*}$ & $-.44^{*}$ & $-.41^{*}$ & $-.30^{*}$ & $-.21^{*}$ & 1.00 & & & \\
\hline 17. On-field prosocial behavior & 2.71 & .58 & -.11 & -.04 & .01 & -.05 & -.02 & -.07 & .04 & -.04 & .14 & .09 & $.21^{*}$ & $.29^{*}$ & $.24^{*}$ & $.30^{*}$ & $.28 *$ & .00 & 1.00 & & \\
\hline 18. Off-field antisocial behavior & 1.75 & .64 & .06 & -.11 & .11 & .03 & -.07 & .01 & -.11 & .05 & -.00 & $-.38^{*}$ & $-.35^{*}$ & $-.31^{*}$ & $-.51^{*}$ & $-.54^{*}$ & $-.22^{*}$ & $.45^{*}$ & $-.21^{*}$ & 1.00 & \\
\hline 19. Off-field prosocial behavior & 2.69 & .52 & -.16 & .00 & .02 & .06 & -.11 & .01 & .06 & -.01 & $.25^{*}$ & .01 & .13 & $.24^{*}$ & $.26^{*}$ & $.26^{*}$ & $.28^{*}$ & -.11 & $.50^{*}$ & .01 & 1.00 \\
\hline
\end{tabular}

$N=331$ athletes, $N=54$ coaches.

${ }^{*} p<.001$.

${ }^{\mathrm{a}} 1=$ indigenous, 2 = non-indigenous. 


\section{On-field antisocial behavior}

From the null-model in Table 2 it can be derived that $8 \%$ of the variance in on-field antisocial behavior could be attributed to between team differences (contextual effect), and $92 \%$ to differences between individual athletes (individual effect). The between team differences were significant, $\chi^{2}(1)=$ $5.19, \mathrm{p}<.05$. The best fitting multilevel regression model, containing three additional predictors $\left(\chi^{2}(3, N=331)=86.70, p<.001\right)$, accounted for $24 \%$ of the variance in on-field antisocial behavior. The proportion of explained variance was $17 \%$ at the individual level (i.e., $18 \%$ of the differences between individual athletes within teams), and $7 \%$ at the contextual level (i.e., $88 \%$ of the between team differences). Athletes' positive attitude toward fair play $(b=-.25)$ and positive perception of their coach's fair play attitude $(b=-.22)$ were both related to less on-field antisocial behavior. Positive fair play attitude of the team was related to less on-field antisocial behavior $(b=-.31)$.

Table 2

Multilevel regression model for on-field antisocial behavior

\begin{tabular}{|c|c|c|c|}
\hline & \multirow[t]{2}{*}{ Null-model } & \multicolumn{2}{|c|}{ Explanatory model } \\
\hline & & $\mathrm{b}$ & $\mathrm{t}$ \\
\hline Intercept & $2.04(.04)$ & & \\
\hline \multicolumn{4}{|l|}{ Individual level } \\
\hline Fair play attitude athlete & & -.25 & $4.93 * * *$ \\
\hline Fair play attitude coach & & -.22 & $4.31 * * *$ \\
\hline \multicolumn{4}{|l|}{ Contextual level } \\
\hline Fair play attitude of the team & & -.31 & $6.13 * * *$ \\
\hline \multicolumn{4}{|l|}{ Variance components } \\
\hline Individual level & $.338(92 \%)$ & .275 & \\
\hline Contextual level & $.031(8 \%)$ & .004 & \\
\hline \multicolumn{4}{|l|}{ Explained varience ${ }^{a}$} \\
\hline Individual level & & $17 \%$ & \\
\hline Contextual level & & $7 \%$ & \\
\hline$\chi^{2}$ & & $86.70 * * *$ & \\
\hline $\begin{array}{l}\mathrm{N}=331 \text { athletes, } \mathrm{N}=43 \text { tean } \\
* * * \mathrm{p}<.001 .\end{array}$ & & & \\
\hline
\end{tabular}




\section{On-field prosocial behavior}

On-field prosocial behavior was attributed to differences at the contextual and individual level for $14 \%$ and for $86 \%$, respectively (see Table 3 ). The between team differences were significant, $x^{2}(1)=16.73, p<.001$. The best fitting multilevel regression model, with three additional predictors $\left(x^{2}\right.$ $(3, N=331)=36.30, p<.001)$, accounted for $18 \%$ of the differences in onfield prosocial behavior. Most of the variance accounted for was distributed at the individual level, namely $13 \%$. The explained variance at the contextual level was $5 \%$. A stronger fair play attitude of the individual athlete as compared to his fellow team members $(b=.17)$ and more relational support from the coach at the individual $(b=.16)$ and team level $(b=.22)$ were related to more on-field prosocial behavior.

Table 3

Multilevel regression model for on-field prosocial behavior

\begin{tabular}{|c|c|c|c|}
\hline & \multirow[t]{2}{*}{ Null-model } & \multicolumn{2}{|c|}{ Explanatory model } \\
\hline & & $\mathrm{b}$ & $\mathrm{t}$ \\
\hline Intercept & $2.72(.04)$ & & \\
\hline \multicolumn{4}{|l|}{ Individual level } \\
\hline Fair play attitude athlete & & .17 & $3.33 * * *$ \\
\hline Relational support by the coach & & .16 & $3.30 * * *$ \\
\hline \multicolumn{4}{|l|}{ Contextual level } \\
\hline Relational support by the coach & & .22 & $3.36 * * *$ \\
\hline \multicolumn{4}{|l|}{ Variance components } \\
\hline Individual level & $.284(86 \%)$ & .259 & \\
\hline Contextual level & $.045(14 \%)$ & .031 & \\
\hline \multicolumn{4}{|l|}{ Explained varience $^{a}$} \\
\hline Individual level & & $13 \%$ & \\
\hline Contextual level & & $5 \%$ & \\
\hline$\chi^{2}$ & & $36.30 * * *$ & \\
\hline $\begin{array}{l}\mathrm{N}=331 \text { athletes, } \mathrm{N}=43 \text { teams. } \\
* * * \mathrm{p}<.001 .\end{array}$ & & & \\
\hline
\end{tabular}




\section{Off-field antisocial behavior}

Off-field antisocial behavior (see Table 4) was attributed to differences between teams and individual athletes for $21 \%$ and $79 \%$, respectively. Here, too, the between team differences were significant, $x^{2}(1)=3.43, p<.001$. The best fitting multilevel regression model, with six additional predictors $\left(\chi^{2}\right.$ $(6, N=331)=154.80, p<.001)$, accounted for $43 \%$ of the variance in offfield antisocial behavior: $22 \%$ of the explained variance was distributed at the individual level and $21 \%$ at the contextual level. Relational support provided by the coach was related to lower involvement in off-field antisocial behavior both at the individual $(b=-.20)$ and team level $(b=-.26)$. Positive attitude toward fair play of the coach, as perceived by the athletes ( $b=-$ $.24)$, higher socioeconomic status $(b=-.11)$, higher levels of verbal intelligence $(b=-.18)$, and higher levels of sociomoral reasoning within the team $(b=-.19)$ were related to less off-field antisocial behavior.

\section{Off-field prosocial behavior}

Only $1 \%$ of the variance in off-field prosocial behavior could be attributed to differences between teams and $99 \%$ to differences between individual athletes. The between team differences were not significant, $\chi^{2}(1)=.16$, ns. Thus, differences in off-field prosocial behavior can only be explained by individual level variables. As we were only interested in contextual effects, we decided not to further analyze off-field prosocial behavior. 
Table 4

Multilevel regression model for off-field antisocial behavior

\begin{tabular}{|c|c|c|c|}
\hline & Null-model & Explanatory & nodel \\
\hline & & $\mathrm{b}$ & $\mathrm{t}$ \\
\hline Intercept & $1.74(.06)$ & & \\
\hline \multicolumn{4}{|l|}{ Individual level } \\
\hline Fair play attitude coach & & -.24 & $5.30 * * *$ \\
\hline Relational support by the coach & & -.20 & $4.31 * * *$ \\
\hline SES & & -.11 & $2.35 *$ \\
\hline Verbal intelligence & & -.18 & $4.20 *$ \\
\hline \multicolumn{4}{|l|}{ Contextual level } \\
\hline Relational support by the coach & & -.26 & $4.71 * * *$ \\
\hline $\begin{array}{l}\text { Sociomoral reasoning about } \\
\text { sports dilemma }\end{array}$ & & -.19 & $3.61 * * *$ \\
\hline \multicolumn{4}{|l|}{ Variance components } \\
\hline Individual level & $.089(79 \%)$ & .001 & \\
\hline Contextual level & $.328(21 \%)$ & .234 & \\
\hline \multicolumn{4}{|l|}{ Explained varience ${ }^{a}$} \\
\hline Individual level & & $22 \%$ & \\
\hline Contextual level & & $21 \%$ & \\
\hline$\chi^{2}$ & & $154.80 * * *$ & \\
\hline $\begin{array}{l}\mathrm{N}=331 \text { athletes, } \mathrm{N}=43 \text { teams. } \\
* \mathrm{p}<.05 . \\
* * * \mathrm{p}<.001\end{array}$ & & & \\
\hline
\end{tabular}

\section{Discussion}

The purpose of this study was to gain insight into the contribution of organized youth sports to antisocial and prosocial behavior in adolescent athletes. Using multilevel analyses, we investigated which factors uniquely predicted on-and off-field antisocial and prosocial behavior in male soccer players. The study revealed that $21 \%$ of the variance in off-field antisocial behavior and $8 \%$ and $14 \%$ of the variance in on-field antisocial and prosocial behavior, respectively, could be attributed to differences among the teams and among their coaches. These differences were characterized by relational support provided by the coach, attitude toward fair play, and sociomoral reasoning about sports dilemmas. The size of the contextual effect for off- 
field antisocial behavior should be considered of practical importance, as it is comparable with the school effect on students' achievements, which multilevel studies have estimated to be approximately 19\% (Scheerens \& Bosker, 1997).

The contextual effect for off-field antisocial behavior was relatively large compared to the contextual effect for on-field antisocial behavior, which suggests that the socializing impact of organized youth sports on antisocial behavior may be larger before or after the match than during the sporting activity itself. A possible explanation may be found in the fact that there is more opportunity for off-field than on-field antisocial behavior. Whereas onfield antisocial behavior is regulated and canalized by the formal and informal rules of the game, off-field antisocial behavior is more diverse and less constrained.

Our study suggests that relational support provided by the coach may protect adolescents participating in competitive activities such as sports against developing antisocial behavior. Relational support was the only factor related to both antisocial and prosocial behavior. Athletes from teams experiencing more relational support from their coach reported more on-field prosocial behavior and less off-field antisocial behavior. Previous studies showed that relational support provided by the coach might even affect antisocial behavior outside the sports context. Rutten et al. (2007) found that coach-athlete relationships of a higher quality were related to less antisocial behavior. Whereas the effect for on-field prosocial behavior in the current study might be explained by the fact that the coach is physically present during the activity and thus able to reward such behavior, off-field behavior is often not seen by the coach and consequently not rewarded.

If it is true that on-field antisocial behavior is primarily dependent on factors inherent in sports participation, it is not surprising that only fair play attitude proved to be associated with on-field antisocial behavior. According to Arnold (1994, 2001), fair play not only entails respect for the rules of the game, but also relates to respect for one's opponents, equal opportunities to perform well, mutual co-operation, fairness, and sportsmanship. The present study is one of the first empirical studies showing the importance of fair play attitude for on-field antisocial behavior in adolescent athletes.

Shields and Bredemeier (1995) hypothesized that if only competitive advantage counts, while morally relevant decisions are being made by the referee or the coach, then participation in sports may go along with temporarily closing down the obligation to take account of other people's needs and desires. As such, Shields and Bredemeier refer (p. 113) to a "bracketed morality that legitimizes a temporary, non-serious suspension of the usual moral obligation to equally consider the needs and desires of all 
persons". Nevertheless, the present findings indicate that sociomoral reasoning in the context of sports varies among athletes and teams, and that variations among teams partially account for off-field antisocial behavior.

Although contextual effects are suggestive of an independent influence of the sports club on adolescents' antisocial and prosocial behavior, an alternative explanation cannot be ruled out. Contextual effects might be the result of self-selection, in the sense that prosocial athletes choose to play sports with other prosocial athletes, while antisocial athletes join antisocial athletes. Another form of self-selection might occur when athletes with certain characteristics are assigned to specific teams or coaches. An argument against self-selection is that the contextual effects were still significant after controlling for variables that may be considered closely related to processes of self-selection, namely educational level of the athletes, cultural and socioeconomic background.

There are some limitations to the current study that need to be taken into account. The contextual effects are possibly even stronger in reality than our research shows, as these effects are systematically underestimated in multilevel analysis. This is due to the fact that all measurement error is distributed at the individual level. Another explanation for the relatively strong individual effects is that contextual influences are filtered and colored by the personal perceptions and experiences of the athletes. Studies with reduced measurement error (e.g., using latent variables) as well studies using observational methods or data from coaches or outsider informants may therefore contribute to a more complete picture.

The number of participating sports clubs was too small to conduct multilevel analyses at the club level also. Therefore, we were unable to distinguish sports club influences from team influences. Furthermore, the cross-sectional character of the study sets limitations to the causal interpretation of the results. Finally, the findings were based on self-reports exclusively. Selfreport instruments assessing antisocial and prosocial behavior, however, generally appear to be reliable and valid (Carlo \& Randall, 2002; Junger-Tas \& Haen Marshall, 1999).

Rees et al. (1990) concluded that participation in sports may not positively influence the development of 'character' in any significant way, unless sports programs are designed to optimize opportunities for social and moral learning. The current study identified team-related factors that, if strengthened, might enhance the positive contribution of sports participation to social functioning in adolescent athletes. Our findings show that the coach may exert a positive influence on athletes' on-and off-field antisocial and prosocial behavior, underscoring that the importance of the quality of 
relationships with adults for the socialization of adolescents (Steinberg, 2001) also applies to leisure activities such as sports. Equipping the coach with the skills to maintain good relationships with the athletes should be a primary target in the curriculum of any coach training institute, and an important aim for sports clubs that want to take responsibility for the educational needs of their young athletes. Our findings also provide support for attempts to stimulate fair play attitude and sociomoral reasoning among team members. More research is needed to identify the group processes that are responsible for team level differences in fair play attitude and sociomoral reasoning.

\section{Acknowledgement}

This study was financially supported by NOC*NSF (the Dutch department of the International Olympic Committee) and the Dutch Fonds1818 (Fund1818).

\section{References}

Arnold, P. J. (1994). Sport and moral education. Journal of Moral Education, 23(1), 75-89.

Arnold, P. J. (2001). Sport, moral development, and the role of the teacher: Implications for research and moral education. Quest, 53, 135-150.

Aziz, S. A. (1998). Aggressive tendencies in Malaysian youth soccer: An examination of individual and contextual factors. Unpublished doctoral dissertation, University of Iowa, Iowa.

Bandura, A. (1977). Social learning theory. New York: General Learning Press.

Barber, B. L., Eccles, J. S., \& Stone, M. R. (2001). Whatever happened to the jock, the brain, and the princess? Young adult pathway linked to adolescent activity involvement and social identity. Journal of Adolescent Research, 16, 429-455.

Bartko, W. T., \& Eccles, J. S. (2003). Adolescent participation in structured and unstructured activities: A person-oriented analysis. Journal of Youth and Adolescence, 32(4), 233-241.

Basinger, K. S., \& Gibbs, J. C. (1987). Validation of the sociomoral reflection objective measure-short form. Psychological Reports, 61, 139-146.

Beam, M. R., Chen, C., \& Greenberger, E. (2002). The nature of adolescents' relationships with their "very important" nonparental adults. American Journal of Community Psychology, 30(2), 305-325.

Begg, D. J., Langley, J. D., Moffitt, T., \& Marshall, S. W. (1996). Sport and 
delinquency: An examination of the deterrence hypothesis in a longitudinal study. British Journal of Sports Medicine, 30(4), 335-341.

Bernstein, B., \& Brandis, W. (1970). Social class differences in communication and control. In W. Brandis (Ed.), Social class, language, and communication (pp. 93-124). London: Routledge.

Biesta, G. J. J., Stams, G. J. J. M., Dirks, E., Rutten, E. A., Veugelers, W., \& Schuengel, C. (2001). Does sport make a difference? An exploration of the impact of sport on the social integration of young people. In J. Steenbergen, P. de Knop, \& A. H. F. Elling (Eds.), Values and norms in sport (pp. 95-113). Oxford: Meyer \& Meyer Sport.

Boom, J. (1991). Collective development and the learning paradox. Human Development, 34, 273-287.

Bredemeier, B. J., \& Shields, D. L. (1986a). Game reasoning and interactional morality. Journal of Genetic Psychology, 147(2), 257-275.

Bredemeier, B. J. L., \& Shields, D. L. L. (1986b). Moral growth among athletes and non-athletes: A comparative analysis. Journal of Genetic Psychology, 147(1), 7-18.

Brugman, D., Podolskij, A. I., Heymans, P. G., Boom, J., Karabanova, O., \& Idobaeva, O. (2003). Perception of moral atmosphere in school and norm transgressive behaviour in adolescents: An intervention study. International Journal of Behavioural Development, 27(4), 289-300.

Carlo, G., \& Randall, B. A. (2002). The development of a measure of prosocial behaviors for late adolescents. Journal of Youth and Adolescence, 31(1), 31-44.

CBS. (1999). Sportbeoefening vanaf 1991 (Sports participation from 1991). Voorburg/Heerlen: CBS.

Crowne, D. P., \& Marlowe, D. (1960). A new scale of social desirability independent of psychopathology. Journal of Consulting Psychology, 24, 349354.

Duncan, S. C., Duncan, T. E., Strycker, L. A., \& Chaumeton, N. R. (2002). Relations between youth antisocial and prosocial activities. Journal of Behavioral Medicine, 25(5), 425-438.

Endresen, I. M., \& Olweus, D. (2005). Participation in power sports and antisocial involvement in preadolescent and adolescent boys. Journal of Child Psychology and Psychiatry, 46(5), 468-478.

Gibbs, J. C., Basinger, K. S., \& Fuller, D. (1992). Measuring the development of sociomoral reflection. Hillsdale, NY: Lawrence Erlbaum.

Goldstein, H. (1995). Multilevel statistical models (2nd ed.). London: Edward Arnold.

Grossman, J. B., \& Rhodes, J. E. (2002). The test of time: Predictors and effects of duration in youth mentoring relationships. American Journal of Community Psychology, 30(2), 199-219.

Guivernau, M., \& Duda, J. L. (2002). Moral atmosphere and athletic aggressive tendencies in young soccer players. Journal of Moral Education, $31(1), 67-85$.

Higgins, A. (1995). Dimensions of the school culture scale: Measuring attitudes, norms and values in educational settings. Fordham: Fordham University. 
Higgins-D'Alessandro, A., \& Sadh, D. (1998). The dimensions and measurement of school culture: Understanding school culture as the basis for school reform. International Journal of Educational Research, 28, 553-569. Higgins, A., Power, C., \& Kohlberg, L. (1984). The relationship of moral judgment to judgments of responsibility. In J. Gewirtz, \& W. Kurtines (Eds.), Morality, moral development, and moral behavior: Basic issues in theory and research. New York: Wiley.

Høst, K., Brugman, D., Tavecchio, L., \& Beem, L. (1998). Students' perception of the moral atmosphere in secondary school and the relationship between moral competence and moral atmosphere. Journal of Moral Education, 27(1), 47-71.

Jensen, A. R. (1998). The g-factor: The science of mental ability. Westport, CT: Praeger Publications.

Junge, A., Dvorak, J., Ro“ sch, D., Graf-Baumann, T., Chomiak, J., \& Peterson, L. (2000). Psychological and sport-specific characteristics of football players. The American Journal of Sports Medicine, 28(5), 22-28.

Junger-Tas, J., \& Haen Marshall, I. (1999). The self-report methodology in crime research. In M. Tonry (Ed.), Crime and justice. A review of research, vol. 25 (pp. 291-367). Chicago: University of Chicago Press, pp. Loland, S., \& McNamee, M. (2000). Fair play and the ethos of sports: An eclectic philosophical framework. Journal of the Philosophy of Sport, 27, 6380.

Luteijn, F., \& Van der Ploeg, F. A. E. (1983). Handleiding GIT (Manual GIT, Groninger Intelligence Test). Lisse: Swets \& Zeitlinger.

Luxbacher, J. (1986). Violence in sport: An examination of the theories of aggression and how the coach can influence the degree of violence in sport. Coaching Review, 9, 14-17.

McHale, S. M., Crouter, A. C., \& Tucker, C. J. (2001). Free-time activities in middle childhood: Links with adjustment in early adolescence. Child Development, 72(6), 1764-1778.

McMahon, J. R. (1990). The psychological benefits of exercise and the treatment of delinquent adolescents. Sports Medicine, 9, 344-351.

Mutrie, N., \& Parfitt, G. (1998). Physical activity and its link with mental, social and moral health in young people. In

S. Biddle, J. Sallis, \& N. Cavill (Eds.), Young and active? Young people and health-enhancing physical activity - evidence and implications (pp. 49-68). London: Health education Authority. Nagin, D. S., \& Tremblay, R. E. (2001). Parental and early childhood predictors of persistent physical aggression in boys from kindergarten to high school. Archives of General Psychiatry, 58, 389-394.

NCYS (National Council of Youth Sports). (2001). Market research. NCYS Membership Survey-2001. Stuart, FL: NCYS.

Ommundsen, Y., Roberts, G. C., Lemyre, P. N., \& Treasure, D. (2003).

Perceived motivational climate in male youth soccer: relations to social-moral functioning, sportspersonship and team norm perceptions. Psychology of Sport and exercise, 4, 397-413.

Parra, G. R., DuBois, D. L., Neville, H. A., \& Pugh-Lilly, A. O. (2002). 
Mentoring relationships for youth: Investigation of a process-oriented model. Journal of Community Psychology, 30(4), 367-388.

Power, F. C., Higgins, A., \& Kohlberg, L. (1989). Lawrence Kohlberg's approach to moral education. New York: Columbia University Press.

Rees, C. R., Howell, F. M., \& Miracle, A. W. (1990). Do high school sports build character? A quasi-experiment on a national sample. The Social Science Journal, 27(3), 303-315.

Rhodes, J. E., Bogatt, G. A., Roffman, J., Edelman, P., \& Galasso, L. (2002). American Journal of Community Psychology, 30(2), 149-155.

Rutten, E. A., Stams, G. J. J. M., Biesta, G. J. J., Schuengel, C., Dirks, E., \& Hoeksma, J. B. (2007). The contribution of organized youth sport to antisocial and prosocial behavior in adolescent athletes. Journal of Youth and Adolescence, 36(3), 255-264.

Scheerens, J., \& Bosker, R. J. (1997). The foundations of educational effectiveness. UK: Pergamon.

Scholte, R. H. C., Van Lieshout, C. F. M., \& Van Aken, M. A. G. (2001). Perceived relational support in adolescence: Dimensions, configurations, and adolescent adjustment. Journal of Research on Adolescence, 11(1), 71-94. Shields, D. L. L., \& Bredemeier, B. J. L. (1995). Character development and physical activity. Champaing, IL: Human Kinetics.

Shields, D., Bredemeier, B., Gardner, D., \& Bostrom, A. (1995). Leadership, cohesion and team norms regarding cheating and aggression. Sociology of Sport Journal, 12, 324-336.

Simon, R. L. (2000). Internalism and internal values in sport. Journal of the Philosophy of Sport, 27, 1-16.

Slicker, E. K., \& Palmer, D. J. (1993). Mentoring at risk high school students: Evaluation of a school-based program.

School Counselor, 40(5), 327-334.

Snijders, T. A. B., \& Bosker, R. J. (1999). Multilevel analysis: An introduction to basic and applied multilevel modeling. London: Sage.

Steinberg, L. (2001). We know some things: Parent-adolescent relationships in retrospect and prospect. Journal of Research on Adolescence, 11, 1-19. Stephens, D. E. (2000). Predictors of likelihood to aggress in youth soccer: An examination of coed and all-girls teams. Journal of Sport Behavior, 23, 311-325.

Stephens, D. E. (2001). Predictors of aggressive tendencies in girls' basketball: An examination of beginning and advanced participants in a summer skills camp. Research Quarterly for Exercise and Sport, 72, 257266.

Stephens, D. E., \& Bredemeier, B. J. (1996). Moral atmosphere and judgments about aggression in girls' soccer: Relationships among moral and motivational variables. Journal of Sport and Exercise Psychology, 18, 158173.

Stevenson, M. J. (1998). Measuring the cognitive moral reasoning of collegiate student-athletes: The development of the Stevenson-Stoll Social Responsibility Questionnaire. Unpublished doctoral dissertation, University of Idaho.

Tamboer, J., \& Steenbergen, J. (2000). Sportfilosofie (Philosophy of sport). 
Leende: Damon.

Van Westerlaak, J. M., Kropman, J. A., \& Collaris, J. W. M. (1990).

Beroepenklapper (Standard educational and occupational classification guide). Nijmegen: ITS.

Veugelers, W., \& De Kat, E. (1998). Opvoeden in het voortgezet onderwijs:

Leerlingen, ouders en docenten over de pedagogische opdracht en de

afstemming tussen gezin en school (Education in middle and high school:

Students, parents, and teachers about their educational tasks in the attunement between family and school). Assen: Van Gorcum.

Weir, K., \& Duveen, G. (1981). Further development and validation of the prosocial behaviour questionnaire for use by teachers. Journal of Child Psychology and Psychiatry, 22, 357-374.

Wouters, L., \& Spiering, W. (1990). Vragenlijst Ongewenst Gedrag (Antisocial Behavior Questionnaire). Amsterdam: GG \& GD Amsterdam.

Zimmerman, M. A., Bingenheimer, J. B., \& Notaro, P. C. (2002). Natural mentors and adolescent resilience: A study with urban youth. American Journal of Community Psychology, 30(2), 221-243.

Zwanepol, F., Berghuis, H., De Groot, E., \& Luteijn, F. (2002). Vergelijkend onderzoek tussen de WAIS-III en de verkorte GIT (Comparative study between the Dutch version of the WAIS-III and the shortened version of the Dutch intelligence test GIT). De Psycholoog, 37(11), 581-587. 